\section{Eculizumab treatment in a patient with hematopoietic stem cell transplantation-asso- ciated thrombotic microan- giopathy and steroid-refractory acute graft versus host disease}

\author{
Cristina Fernández, Ana Lario, \\ Rafael Forés, Rafael Cabrera \\ Department of Hematology, Hospital \\ Universitario Puerta de Hierro \\ Majadahonda, Madrid, Spain
}

\section{Abstract}

A 30-year-old man with acquired aplastic anemia underwent an HLA-identical bone marrow transplant. He developed a grade III acute graft versus host disease (GVHD) refractory to various lines of treatment. On post-transplant day 196, he was diagnosed with stem cell transplantation-associated thrombotic microangiopathy (HSCT-TMA) and he received treatment with eculizumab $900 \mathrm{mg}$ iv weekly for 4 doses followed by a single dose of 1200 mg 2 weeks later. After the first dose of eculizumab, the patient ceased to require transfusions and a progressive improvement in analytical parameters for microangiopathy was observed until their complete normalization. Coinciding with the improved of HSCTTMA, the patient presented a clear response to his acute GVHD with disappearance of the diarrhea and bilirubin normalization. He was discharged eight weeks after the start of treatment. Unfortunately, one month later, the patient was readmitted for a GVHD relapse and he died two weeks later by an acute respiratory distress syndrome. In our case, the rapid clinical and analytical response to early treatment with eculizumab supports the implication of the complement in HSCT-TMA and suggests that the drug has a beneficial effect when used as coadjuvant therapy in acute GVHD.

\section{Introduction}

An article recently published demonstrated the efficacy of eculizumab in the treatment of children with severe hematopoietic stem cell transplantation-associated thrombotic microangiopathy (HSCT-TMA). ${ }^{1}$ We report the case of an adult with HSCT-TMA successfully treated with eculizumab.

HSCT-TMA is a rare but very serious complication of allogeneic hematopoietic progenitor stem cell transplantation. Several factors have been implicated in the endothelial damage which leads to HSCT-TMA: calcineurin inhibitors, acute graft versus host disease (GVHD) and cytomegalovirus (CMV) infection; however, in recent years another mechanism has been described in which complement deregulation plays an important role. Therefore complement-modulating therapies are beginning to gain ground in the treatment of this complication. 2,3

\section{Case Report}

We report the case of a 30-year-old man, diagnosed with very serious acquired bonemarrow aplasia in July 2014. He underwent progenitor stem cell transplantation of bone marrow from his HLA-identical sister in July 2014. The conditioning regimen consisted of cyclophosphamide (30 mg/kg/day, -7 to -4 ), fludarabine $(30 \mathrm{mg} / \mathrm{m} 2 /$ day, -5 to -2$)$ and antithymocyte globulin $(2.5 \mathrm{mg} / \mathrm{kg} / \mathrm{day},-3$ to -1). GVHD prophylaxis was performed with tacrolimus and methotrexate. On post-transplant day 47, the patient developed acute cutaneous and liver GVHD (grade II) which initially responded to treatment with corticosteroids and etanercept. The patient was readmitted on post-transplant day 116 with diarrhea and hyperbilirubinemia $(1.7 \mathrm{mg} / \mathrm{dL}$, normal values $0.3-1.1 \mathrm{mg} / \mathrm{dL}$ ) and colonoscopy confirmed the existence of acute intestinal GVHD. After the diagnosis of acute grade III GVHD, which was refractory to steroids, he sequentially received various lines of treatment (corticosteroids, mesenchymal stromal cells and sirolimus) without any response.

On post-transplant day 189 , the patient developed severe bloody diarrhea (up to 3000 $\mathrm{mL} /$ day) followed by persistent rectal bleeding that required intense transfusional support and treatment with activated Factor VII (5 $\mathrm{mg} / 2 \mathrm{~h} \times 6$ doses). A new colonoscopy was performed and the colonic mucosa biopsy confirmed worsening of the intestinal GVHD without histological evidence of HSCT-TMA (Figure 1). ${ }^{4}$ Biochemistry showed LDH 765 IU/L (normal values $230-460 \mathrm{IU} / \mathrm{L}$ ), total bilirubin 0.7 $\mathrm{mg} / \mathrm{dL}$ (normal values $0.3-1.1 \mathrm{mg} / \mathrm{dL}$ ), hemoglobin $8.5 \mathrm{~g} / \mathrm{dL}$, platelets $42 \times 10^{9} / \mathrm{L}$ and normal coagulation tests. Treatment was then initiated with one dose of pentostatin ( $4 \mathrm{mg} / \mathrm{m} 2 \mathrm{iv}$ ) and alemtuzumab (20 mg sc 3 times/week for 2 weeks).

One week after the administration of pentostatin, and with persistent gastrointestinal bleeding, biochemistry showed hyperbilirubinemia (total bilirubin $6.4 \mathrm{mg} / \mathrm{dL}$, direct bilirubin $5.5 \mathrm{mg} / \mathrm{dL}$, normal values $0.0-0.5$ $\mathrm{mg} / \mathrm{dL}$ ) and elevated LDH (2700 IU/L). The blood count revealed profound anemia (up to $6.8 \mathrm{~g} \mathrm{Hb} / \mathrm{dL})$, reticulocytosis $\left(0.3 \times 10^{9} / \mathrm{L}\right)$,
Correspondence: Rafael Forés Cachón, Servicio de Hematología y Hemoterapia, Hospital Puerta de Hierro, calle Joaquín Rodrigo 2, Majadahonda, 28222 Madrid, Spain.

Tel.: +34.91.191.6811; +34.91.191.7809 - Fax: +34.91 .191 .7862 .

E-mail: rafael.fores@salud.madrid.org

Key words: Eculizumab; thrombotic microangiopathy; acute graft versus host disease.

Acknowledgments: the authors wish to thank Martin Hadley-Adams for translating the manuscript.

Contributions: the authors contributed equally.

Conflict of interest: the authors declare no potential conflict of interest.

Received for publication: 9 July 2015

Revision received: 16 october 2015.

Accepted for publication: 20 October 2015.

This work is licensed under a Creative Commons Attribution NonCommercial 3.0 License (CC BYNC 3.0).

(C) Copyright C. Fernández et al., 2015

Licensee PAGEPress, Italy

Hematology Reports 2015; 7:6107

doi:10.4081/hr.2015.6107

thrombocytopenia $39 \times 10^{9} / \mathrm{L}$ and the presence of numerous schistocytes in blood smear (6\%). Other laboratory findings were: negative direct Coombs test, undetectable haptoglobin, proteinuria (30 mg/dL), normal ADAMST13 activity (94\%) and normal complement proteins (C3 and $\mathrm{C4}$ ). These results led to the diagnosis of HSCT-TMA. ${ }^{5}$

The patient had no neurological symptoms or renal failure. PCR for both CMV and Epstein Barr virus were negative. On the day that the patient was diagnosed with HSCT-TMA, treatment was initiated with eculizumab $900 \mathrm{mg}$ iv weekly for 4 doses followed by a single maintenance dose of $1200 \mathrm{mg} 2$ weeks later. After the first dose of eculizumab, the patient ceased to require transfusions and a progressive improvement in analytical parameters for microangiopathy was observed until their complete normalization after 7 weeks (Hb 11.4 $\mathrm{g} / \mathrm{dL}$, platelets $164 \times 10^{9} / \mathrm{L}$, no schistocytes, bilirubin $0.8 \mathrm{mg} / \mathrm{dL}$ and $450 \mathrm{LDH}$ IU/L). CH50 determinations showed complement activity inhibition after each dose had been administered. Coinciding with the improved of HSCTTMA, the patient presented a clear response to his acute GVHD with disappearance of the diarrhea and bilirubin normalization (Figure 2), although it has not been documented histologically. He was discharged eight weeks after the start of treatment (post-transplant day 

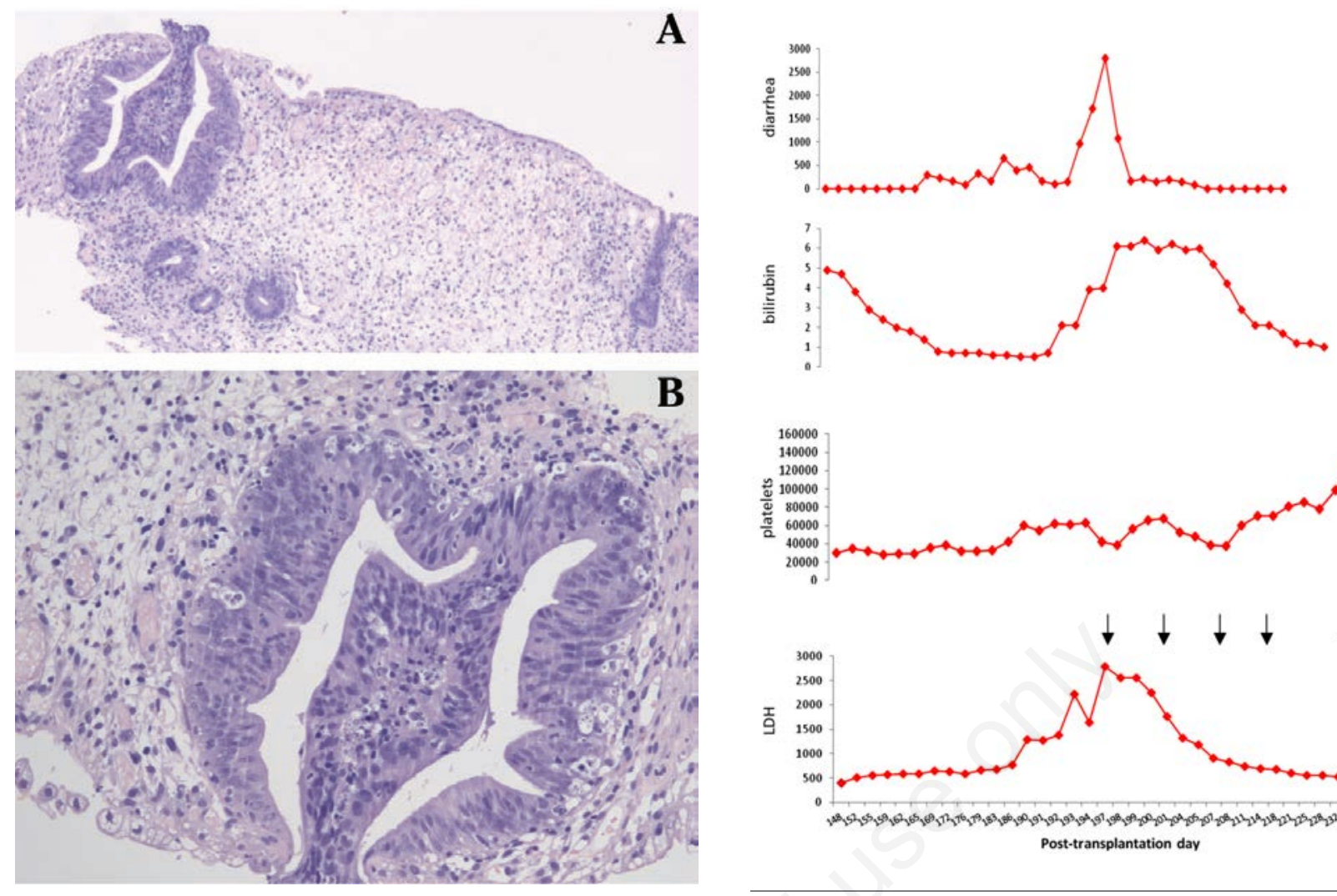

Figure 1. A) Colon biopsy with acute graft versus host disease (GVHD); B) colonic mucosa with apoptotic bodies in crypts
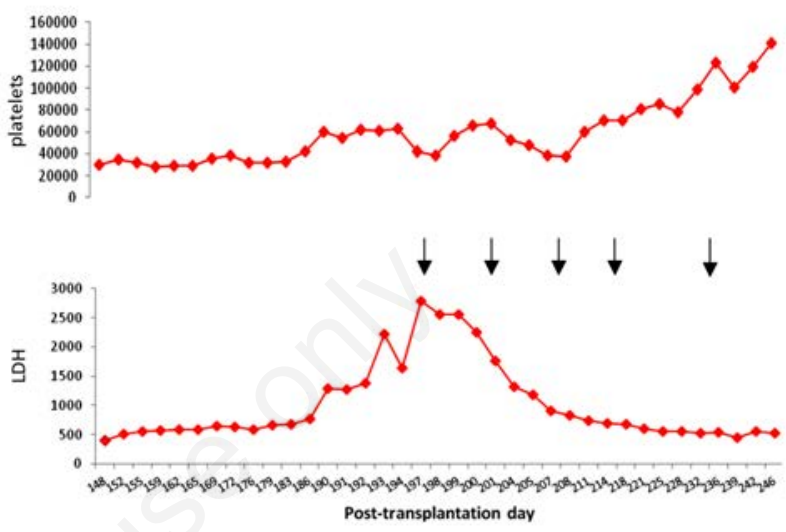
(GVHD).

Figure 2. Levels of diarrhea $(\mathrm{mL})$, bilirubin $(\mathrm{mg} / \mathrm{dL})$, platelets $\left(\times 10^{9}\right)$ and $\mathrm{LDH}(\mathrm{IU} / \mathrm{dL})$ after transplantation.

257). Unfortunately, one month later, the patient was readmitted by diarrhea; a new colonoscopy showed intestinal GVHD relapse. The patient died two weeks after admission because of acute respiratory distress syndrome of unknown cause, with diffuse bilateral infiltrates, cardiomegaly and right pleural effusion in chest CT.

\section{Discussion and Conclusions}

The treatment for HSCT-TMA is not welldefined. Plasma exchange, defibrotide, rituximab and basiliximab have been used with variable response rates. We started eculizumab instead of plasma exchange for the poor results of this treatment in HSCT-TMA cases associated with acute GVHD. ${ }^{6,7}$ In our case, the rapid clinical and analytical response to early treatment with eculizumab (a humanized monoclonal antibody against complement fraction 5) supports the implication of the complement in its pathophysiology. The drug was well tolerated without any side effects. The rapid response of a severe, refractory GVHD is noteworthy and suggests that the drug has a beneficial effect when used as coadjuvant therapy in this situation. More cases and studies would be required to confirm these data.

\section{References}

1. Jodele S, Fukuda T, Vinks A, et al. Eculizumab therapy in children with severe hematopoietic stem cell transplantation-associated thrombotic microangiopathy. Biol Blood Marrow Transplant 2014;20:518-25.

2. Okano M, Sakata N, Ueda S, Takemura T. Recovery from life-threatening transplantation-associated thrombotic microangiopathy using eculizumab in a patient with very severe aplastic anemia. Bone Marrow Transplant 2014;49:1116-8.

3. Peffault de Latour R, Xhaard A, FremeauxBacchi V, et al. Successful use of eculizum- ab in a patient with post-transplant thrombotic microangiopathy. $\mathrm{Br} \mathrm{J}$ Haematol 2013;161:279-80.

4. Inamoto $\mathrm{Y}$, Ito $\mathrm{M}$, Suzuki $\mathrm{R}$, et al. Clinicopathological manifestations and treatment of intestinal transplant-associated microangiopathy. Bone Marrow Transplant 2009;44:43-9.

5. Jodele S, Davies SM, Lane A, et al. Diagnostic and risk criteria for HSCTassociated thrombotic microangiopathy: a study in children and young adults. Blood 2014;124:645-53.

6. Llamas P, Romero R, Cabrera R, et al. Management of thrombotic microangiopathy following allogeneic transplantation: what is the role of plasma exchange? Bone Marrow Transplant 1997;20:305-6.

7. Kennedy GA, Kearey N, Bleakley S, et al. Transplantation-associated thrombotic microangiopathy: effect of concomitant GVHD on efficacy of therapeutic plasma exchange. Bone Marrow Transplant 2010;45:699-704. 